\title{
Health and fitness of young people: what is the role of sport?
}

\section{Margo Mountjoy}

President Rogge in his opening address at the Olympic Movement in Society Congress in Copenhagen, 2009, expressed his concern over the health of young people globally and the importance of the role of sport in society in addressing the issue:

In the late 1800s, de Coubertin worried that youth in his native France were turning away from physical activity. Today, we see the same problem in the growing rate of youth obesity throughout the world. . We are here to make sure that the Olympic Movement will continue to serve athletes, the world's youth and society at large for decades to come. ${ }^{1}$

One of the themes during the Olympic Movement in Society Congress was 'Olympism and Youth'. Following the presentations and discussions in Copenhagen on this theme, Recommendation \#51 was proposed as guidance for members of the Olympic Family:

\#51 Everyone involved in the Olympic Movement must become more aware of the fundamental importance of physical activity and sport for a healthy life style, not least in the growing battle against obesity, and must reach out to parents and schools as part of a strategy to counter the rising inactivity of young people. ${ }^{2}$

Dr Rogge's opening address and the subsequent Recommendation (\#51) from the Olympic Congress underscores the importance of the public health issue of the health and fitness of young people globally. According to the WHO, physical inactivity is the fourth leading risk factor for global mortality following hypertension, tobacco use and high blood glucose contributing to 3.2 million deaths globally per year. Sixty per cent of all global deaths can be attributed to non-communicable diseases. Thirty-one per cent of adults around the world are physically inactive and $5.5 \%$ of all deaths globally can be attributed to inactivity, including

Correspondence to Dr Margo Mountjoy, IOC Medical Commission, Dept of Family Practice, McMaster University, Waterloo EWFHT, 175 Alma Street, Rockwood, Ontario NOB 2K0, Canada; mmsportdoc@aol.com cardiovascular disease, diabetes mellitus and some cancers. ${ }^{3}$

According to the United Nations Task Force on Sports for Development and Peace, sport participation is instrumental in ensuring physical health and wellbeing in young people. In agreement with Recommendation \#51 of the Olympic Congress, the United Nations has also identified the important role of sport in promoting healthy activity for children. The United Nations Task Force developed four objectives for the Sports for Development and Peace project:

1. To raise awareness of the serious health consequences of inactivity and obesity in children based on the provision of evidence-based information.

2. To provide recommendations on the prevention and management of this health issue.

3. To motivate sport organisations and governments to collaborate in promoting healthy fitness in children.

4. To encourage further scientific research in this field. ${ }^{4}$

In 2010, the International Olympic Committee (IOC) and the WHO signed a Memorandum of Understanding, agreeing "to join efforts and to cooperate. . . to promote healthy lifestyles, physical activity and sport among the communities." This collaboration illustrates the intention of the IOC to expand its mandate beyond the care of the elite athlete to also address global public health issues. According to the $\mathrm{WHO}$, interventions to reduce noncommunicable diseases require adequate and appropriate education to empower and encourage behaviour changes by individuals, families and communities. ${ }^{6,7}$ It is well established that the acquisition of knowledge and the development of healthy routines in childhood extend into adulthood. ${ }^{8}$ As a result of this new mandate and in light of the importance of education in the success of influencing behavioural change, the IOC convened a Consensus Meeting in January 2011 to discuss the role of sport and physical activity in addressing the health and fitness of young people globally. There was a critical review of the scientific base in this field with the aim of providing recommendations and identifying potential solutions through the collaboration of sport with existing programmes in this field.

This special edition of the British Journal of Sports Medicine is devoted to the outcomes of this IOC Consensus Meeting. The summary paper of the proceedings is the "International Olympic Committee consensus statement on the health and fitness of young people through physical activity and sport." In addition to the Consensus paper, supporting scientific papers are included in this special edition. The first two papers review the current scientific evidence on current levels of fitness and activity in young people. The health risks of physical inactivity are reviewed including the risks of cardiovascular disease, metabolic disease, obesity, bone disease, mental health issues and sports injury. Two papers assess the phenomenon of physical inactivity by investigating the correlates of physical activity and the determinants of sedentary behaviour. Two reviews of existing intervention programmes look at evidence from both the school-based interventions as well as the community-based interventions. The final paper in the series looks at the 'Context for Action', which addresses the role of various organisations and institutions in the issue of sport participation and inactivity in youth.

In conclusion, sport has an important role to play in the current global health crisis of rising morbidity and mortality from non-communicable diseases caused by physical inactivity, already starting at a young age. Together with other partners in intergovernmental organisations, government, education and healthcare sectors, sport can be instrumental in invoking behaviour changes in young people to positively affect global health.

Participation in sport has significant physical benefits, contributing to people's ability to lead long and healthy lives, improving well-being, extending life expectancy and reducing the likelihood of several major non-communicable diseases. ${ }^{4}$

Acknowledgements The author would like to thank the members of the working group for their valuable contributions. In particular, the assistance of the expert group (Willem van Mechelen, Neil Armstrong and Lyle Micheli) is greatly appreciated. Finally, the author would like to thank the IOC for its leadership and support to this health initiative.

Competing interests None.

Provenance and peer review Not commissioned; internally peer reviewed.

Accepted 13 May 2011

Published Online First 15 June 2011

Br J Sports Med 2011;45:837-838 doi:10.1136/bjsports-2011-090184 


\section{REFERENCES}

1. Rogge J. Opening Address. XIII Olympic Congress: The Olympic Movement in Society. Proceedings from the XIII Olympic Congress, 3 October 2009, Copenhagen, Demark

2. Recommendations of Theme: 'Olympism and Youth' XIII Olympic Congress: The Olympic Movement in Society. Proceedings from the XIII Olympic Congress, 5 October 2009, Copenhagen, Demark.

3. World Health Organization. Report on Global Health Risks. Geneva: WHO, 2009.
4. United Nations Inter-Agency Task Force. Sport for Development and Peace: Towards Achieving the Millennium Development Goals. United Nations, New York, 2003.

5. Occupational Health and Safety. WHO, IOC Sign Healthy Activity Pact. 2010. IOC Signs Memorandum of Understanding with World Health Organization. Lausanne, Switzerland . 21 July 2010. http://www. olympic.org/media?articleid $=94858$ (accessed 1 Jun 2011).
6. World Health Organization. The World Health Report 2002: Reducing Risks, Promoting Healthy Life. Geneva: WHO, 2002.

7. World Health Organization. Global Strategy on Diet, Physical Activity and Health. Geneva: WHO, 2004.

8. Dobbins M, De Corby K, Robeson P, et al. Schoolbased physical activity programs for promoting physical activity and fitness in children and adolescents aged 6-18. Cochrane Database Syst Rev 2009:1:CD007651.

$\underline{\underline{m}}$

$c$

0 